Cite this: RSC Adv., 2017, 7, 4479

Received 24th October 2016 Accepted 26th December 2016

DOI: $10.1039 / c 6 r a 25767 d$

www.rsc.org/advances

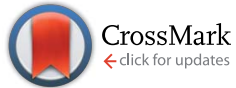

\section{Identification and characterization of in vitro phase I and reactive metabolites of masitinib using a LC- MS/MS method: bioactivation pathway elucidation $\dagger$}

\begin{abstract}
Sawsan M. Amer, ${ }^{a}$ Adnan A. Kadi, ${ }^{b}$ Hany W. Darwish ${ }^{\text {ab }}$ and Mohamed W. Attwa*ab
Masitinib is a selective tyrosine kinase inhibitor (TKI). It is currently registered in Europe for the treatment of mast cell tumors in dogs. The current study reports the identification and characterization of fourteen phase I metabolites of masitinib by reversed phase liquid chromatography triple quadrupole mass spectrometry (LC-QqQ-MS). Phase I metabolic reactions were reduction, demethylation, hydroxylation, oxidation and $\mathrm{N}$-oxide formation. Structures of the proposed phase I metabolites showed high lability to form reactive metabolites. So incubation was performed in the presence of $1.0 \mathrm{mM} \mathrm{GSH}$ or $1.0 \mathrm{mM} \mathrm{KCN}$ to check for reactive metabolites. No GSH adduct was found, while eight cyano adduct structures were determined based on full MS scan and $M^{2}$ scan data for each metabolite. Interestingly, a literature review showed no previous studies have been made on the in vitro metabolism of masitinib or detailed structural identification of the formed metabolites.
\end{abstract}

\section{Introduction}

Nowadays, cancer is considered a major cause of death. ${ }^{1}$ Four and half million new cancer cases have been reported in developed countries. ${ }^{2,3}$ Distributed cancer was recently treated by molecular targeting strategies based upon discovering the tumor suppressors and oncogenes involved in the progress of human cancers. ${ }^{4}$

Tyrosine kinases are enzymes that catalyse the transfer of the $\gamma$ phosphate of ATP to the tyrosine hydroxyl groups on target proteins. They initiate or stop many functions inside living cells. ${ }^{5}$ Controlling the activity of tyrosine kinase in the cell regulates many important processes such as cell cycle, proliferation and cell death. Growth factor receptor-mediated signalling, in many cases, drives the abnormal proliferation characteristics of cancer. The failure of the control mechanism in tumor cells leads to excessive phosphorylation. ${ }^{6,7}$ There are around 60 receptor tyrosine kinases that have been known. Tyrosine kinase inhibitors (TKIs) are considered a very important class of targeted therapy which interferes with specific cell signalling pathways that allow targeting selected malignancies. $^{8}$

${ }^{a}$ Analytical Chemistry Department, Faculty of Pharmacy, Cairo University, Kasr El-Aini St., Cairo 11562, Egypt

${ }^{b}$ Department of Pharmaceutical Chemistry, College of Pharmacy, King Saud University, P. O. Box 2457, Riyadh, 11451, Kingdom of Saudi Arabia. E-mail: mzeidan@ksu.edu. sa; Fax: +966114676 220; Tel: +9661146 70237

$\dagger$ Electronic supplementary information (ESI) available. See DOI: $10.1039 / \mathrm{c} 6 \mathrm{ra} 25767 \mathrm{~d}$
Masitinib (Fig. 1) is a TKI used in the treatment of mast cell tumors in dogs. ${ }^{9}$ It is currently registered in Europe for the treatment of mast cell tumors in dogs. ${ }^{10}$ It acts selectively targeting mainly wild type forms and mutated c-kit receptor (c-Kit R), platelet-derived growth factor receptors (PDGFR $\alpha$ ) $\beta$ ), LCK gene, LYN gene, fibroblast growth factor receptor 3 (FGFR3) and focal adhesion kinase (FAK). It is considered to be the first approved veterinary therapy used as anticancer for the treatment of unresectable canine mast cell tumors (CMCTs), which harbors activating (c-Kit R) mutations at dose of $12.5 \mathrm{mg} \mathrm{kg}{ }^{-1}$ per day. ${ }^{11}$ Masitinib is distributed under the trade name Masivet in Europe since the second part of 2009. It is also available for veterinaries in the USA under the trade name Kinavet since 2011. It exhibits more activity and selectivity against KIT than imatinib in in vitro studies. ${ }^{12}$

The current work reports the identification of fourteen metabolites in addition to eight cyanide adducts that elucidate the bioactivation pathways and may provide hints for the observed clinical adverse effects of masitinib. ${ }^{10}$ No GSH

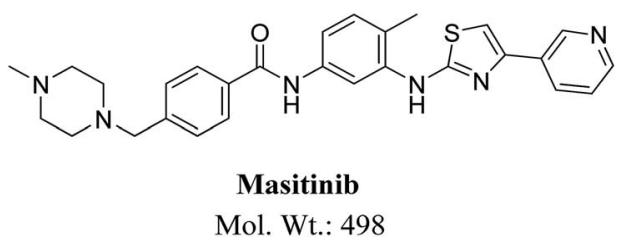

Fig. 1 Chemical structure of masitinib. 

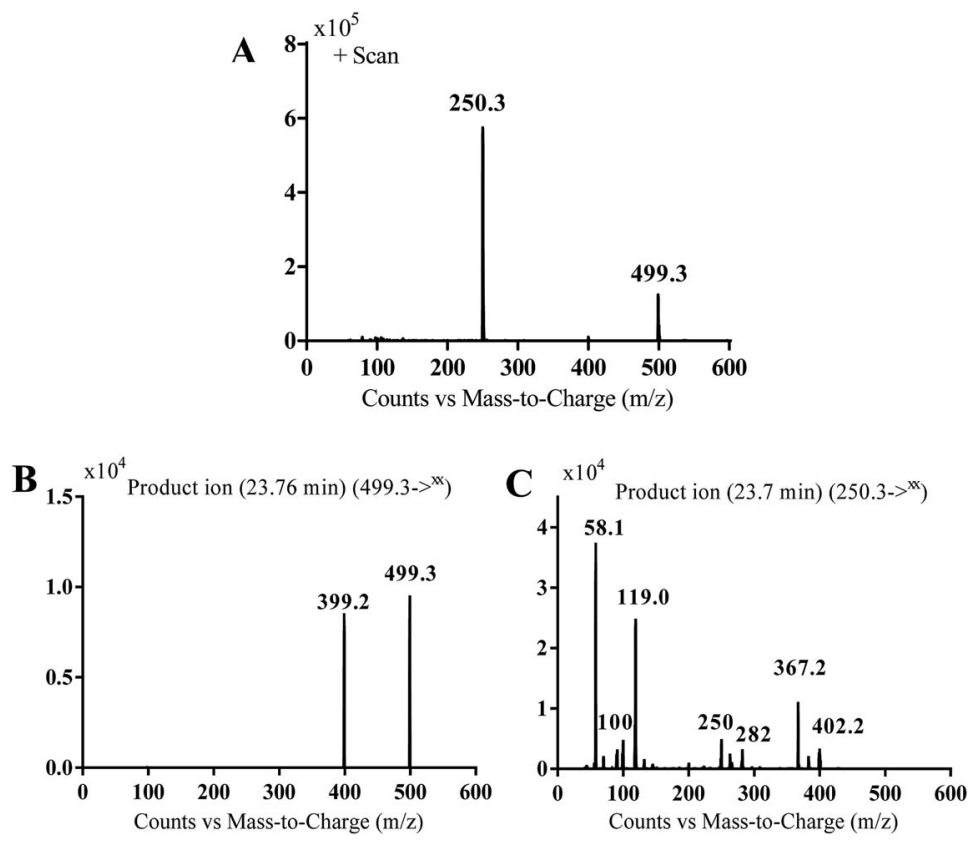

Fig. $2 M S$ scan spectrum for masitinib (A). $M S^{2}$ mass spectrum of $[M+H]^{+}$ion $(m / z 499)(B) . M S^{2}$ mass spectrum of $[M+2 H]^{2+}(m / z 250)(C)$.

adduct was detected in case of incubation of masitinib with GSH. Bioactivation is responsible for observed toxicities including hepatotoxicity, ${ }^{\mathbf{1 0} 13-15}$ the experiments were performed in vitro and focused on the structural identification of the produced in vitro metabolites along with the cyanide adducts.

\section{Chemicals and methods}

\subsection{Chemicals}

RLMs were prepared in-house using Sprague Dowley rats. ${ }^{16}$ Animals' maintenance was performed following the guidelines of Animal Care Center, College of Pharmacy, King Saud University and approved by Local Animal Care and Use

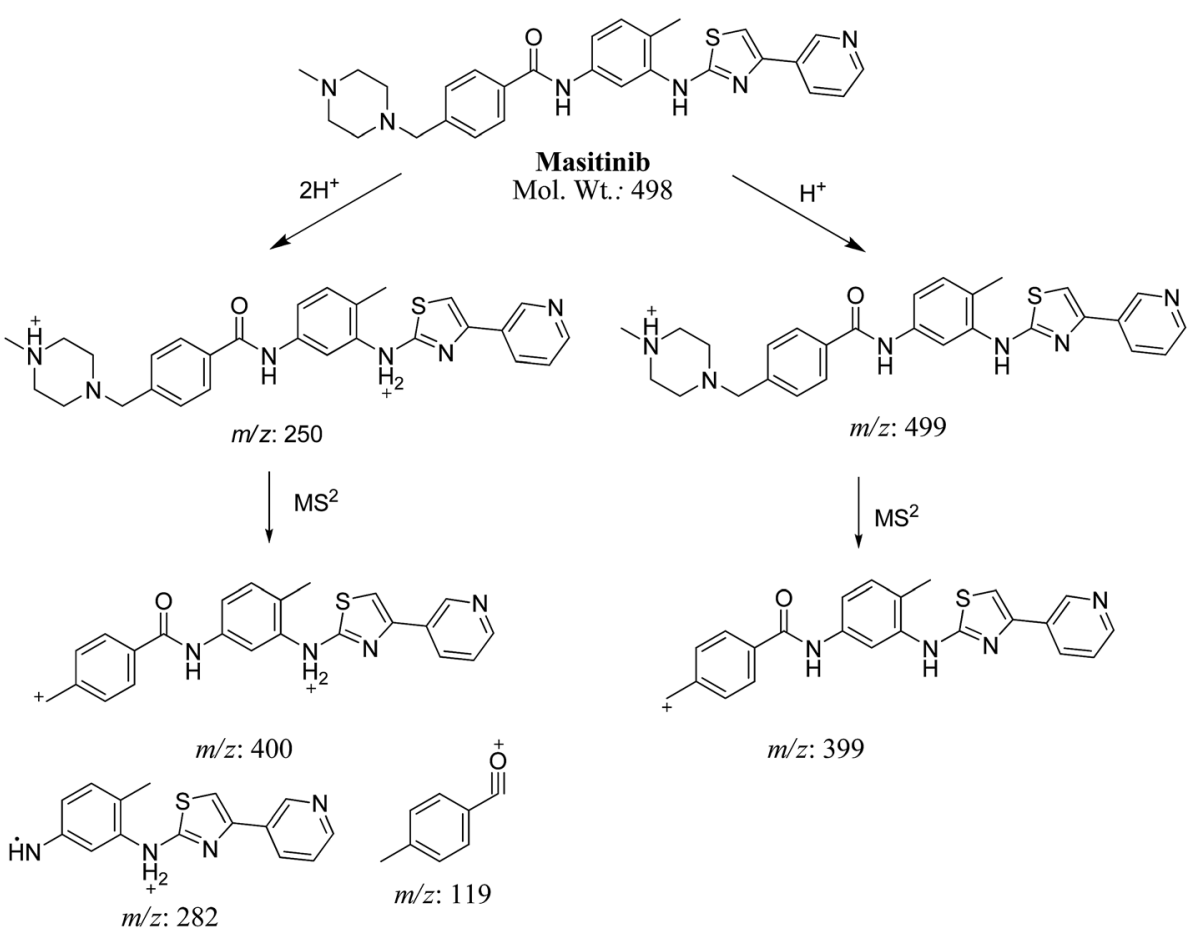

Scheme 1 Fragmentation pattern for masitinib $[\mathrm{M}+\mathrm{H}]^{+}$at $m / z 499$ and $[\mathrm{M}+2 \mathrm{H}]^{2+}$ at $m / z 250$. 
Table 1 In vitro phase I metabolites of masitinib

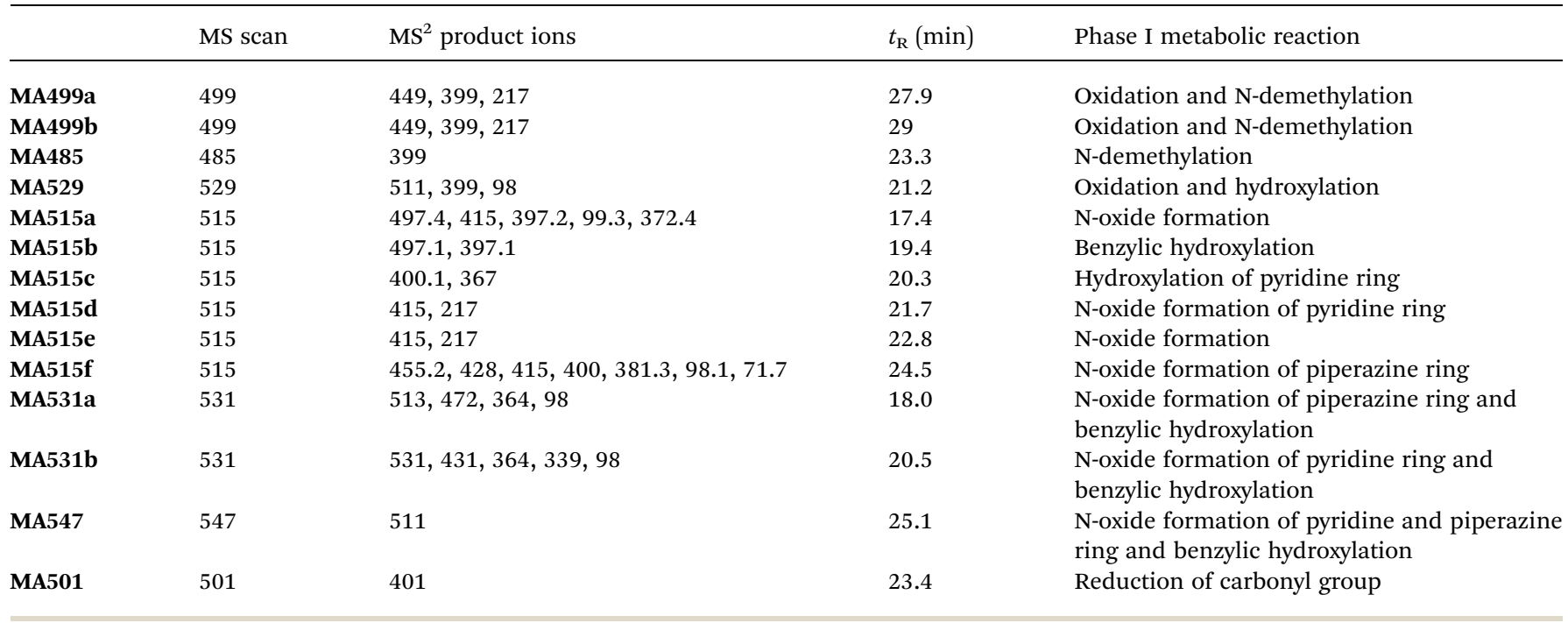

Committee of King Saud University. Masitinib was bought from LC Laboratories (Woburn, MA, USA). Ammonium formate, HPLC grade acetonitrile (ACN), potassium cyanide
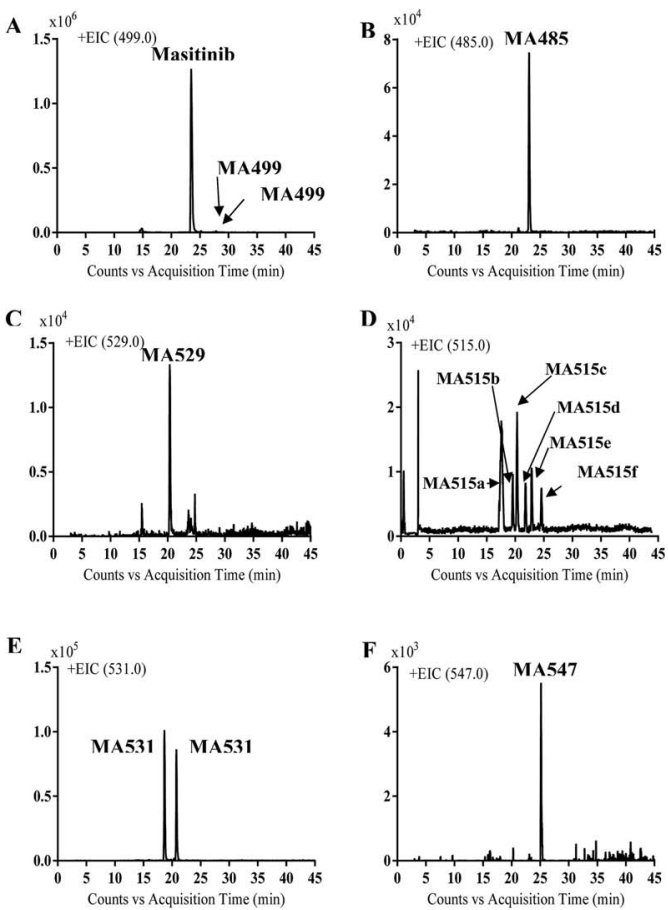

G $\times 10^{3}$

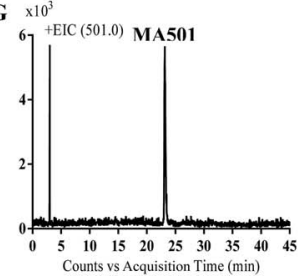

Fig. 3 EICs of molecular ion peaks at $m / z 499$ (A), 485 (B), 529 (C), 515 (D), $531(E), 547(F)$ and $501(G)$ corresponding to masitinib or one of its phase I metabolites.
(KCN) and formic acid were purchased from Sigma-Aldrich (West Chester, PA, USA). HPLC water was obtained from Milli-Q plus purification system, Millipore, Waters (Millipore, Bedford, MA, USA).

\subsection{Chromatographic conditions}

Study of masitinib fragmentation pattern was performed using an Agilent HPLC 1200 connected to triple quadrupole mass spectrometer (Agilent 6410 QqQ) by direct injection on a connector instead of a column. Fragmentation study was then followed by a biotransformation technique; in which masitinib metabolites were produced in vitro and resolved with LC-QqQMS. Incubation of masitinib was performed with rat liver microsomes (RLMs) with and without KCN or GSH.

Chromatographic separation for extract of the incubation mixture was performed on an Agilent HPLC 1200 series system. The chromatography was performed on reversed phase $\mathrm{C}_{18}$ column (Agilent eclipse plus, $50 \mathrm{~mm} \times 2.1 \mathrm{~mm}$ and $1.8 \mu \mathrm{m}$<smiles>Cc1ccc(C(=O)Nc2ccc(C)c(Nc3nc(-c4cccnc4)cs3)c2)cc1</smiles>

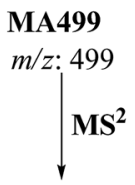<smiles></smiles>

$m / z: 217$<smiles>Cc1ccc(NC(=O)c2ccc(F)cc2)cc1Nc1nc(-c2cccnc2)cs1</smiles>

$m / z: 399$
Scheme 2 Fragmentation pattern of MA499a and MA499b. 

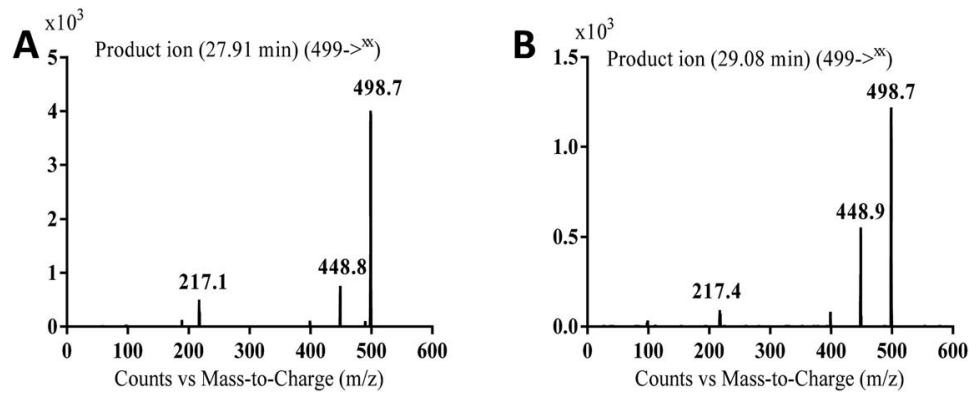

Fig. $4 \mathrm{MS}^{2}$ mass spectra of molecular ion peaks at $m / z$ 499: MA499a (A) and MA499b (B).

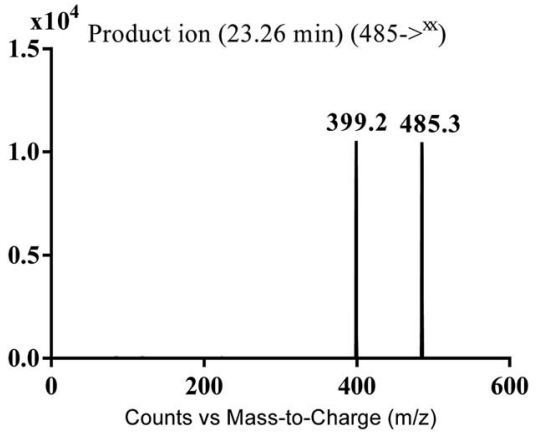

Fig. $5 \mathrm{MS}^{2}$ mass spectra of MA485 molecular ion peak at $\mathrm{m} / \mathrm{z} 485$.

particle size). Column temperature was maintained constant at $24{ }^{\circ} \mathrm{C}$. The flow rate of the mobile phase was $0.2 \mathrm{~mL} \mathrm{~min}{ }^{-1}$. Binary system was used for separation of incubation matrix components that consisted of solvent A which is $10 \mathrm{mM}$ ammonium formate (pH: 4.2) and solvent B which is ACN. The stepwise gradient was 5 to $40 \%$ B (0-30 min), 40\% B (30-40 $\mathrm{min}), 40$ to $5 \% \mathrm{~B}(40-45 \mathrm{~min})$. The post time was 15 minutes. Injection volume of sample was $10 \mu \mathrm{L}$ with a total run time of 45 minutes. Flow injection analysis was used to optimize all mass parameters for masitinib. $\mathrm{MS}^{2}$ mass spectra for masitinib and its metabolites were generated in the collision cell. Detection was performed on QqQ MS detector, operated with an ESI source in the positive ionization mode. Low purity nitrogen was used as drying gas at a flow rate of $12 \mathrm{~L} \mathrm{~min}^{-1}$ and high purity nitrogen as collision gas at a pressure of 60 psi. Source temperature and capillary voltage were set at $350{ }^{\circ} \mathrm{C}$ and $4000 \mathrm{~V}$, respectively. Fragmentor voltage was set at $110 \mathrm{~V}$ with collision energy of $15 \mathrm{~V}$ for masitinib, its phase I metabolites and cyano adducts.

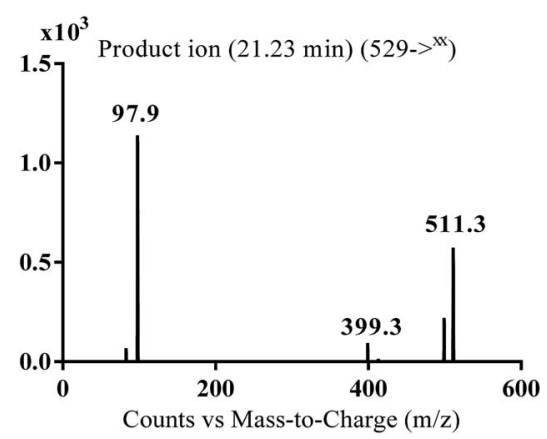

Fig. $6 \mathrm{MS}^{2}$ mass spectrum of MA529 molecular ion peak at $\mathrm{m} / z 529$.<smiles>Cc1ccc(C(=O)Nc2ccc(C)c(Nc3nc(-c4cccnc4)cs3)c2)cc1</smiles><smiles>Cc1ccc(NC(=O)c2ccc(CN3CCN(C)C(=O)C3)cc2)cc1Nc1nc(-c2cccnc2)cs1</smiles>

$m / z: 511$<smiles>C[C@H]1CCN=CC1=O</smiles>

$m / z: 98$

Scheme 4 Fragmentation pattern of MA529.<smiles>Cc1ccc(C(=O)Nc2ccc(C)c(Nc3nc(-c4cccnc4)cs3)c2)cc1</smiles>

MA485

$m / z: 485$<smiles>Cc1ccc(NC(=O)c2ccc(F)cc2)cc1Nc1nc(-c2cccnc2)cs1</smiles>

$m / z: 399$

Scheme 3 Fragmentation pattern of MA485. 

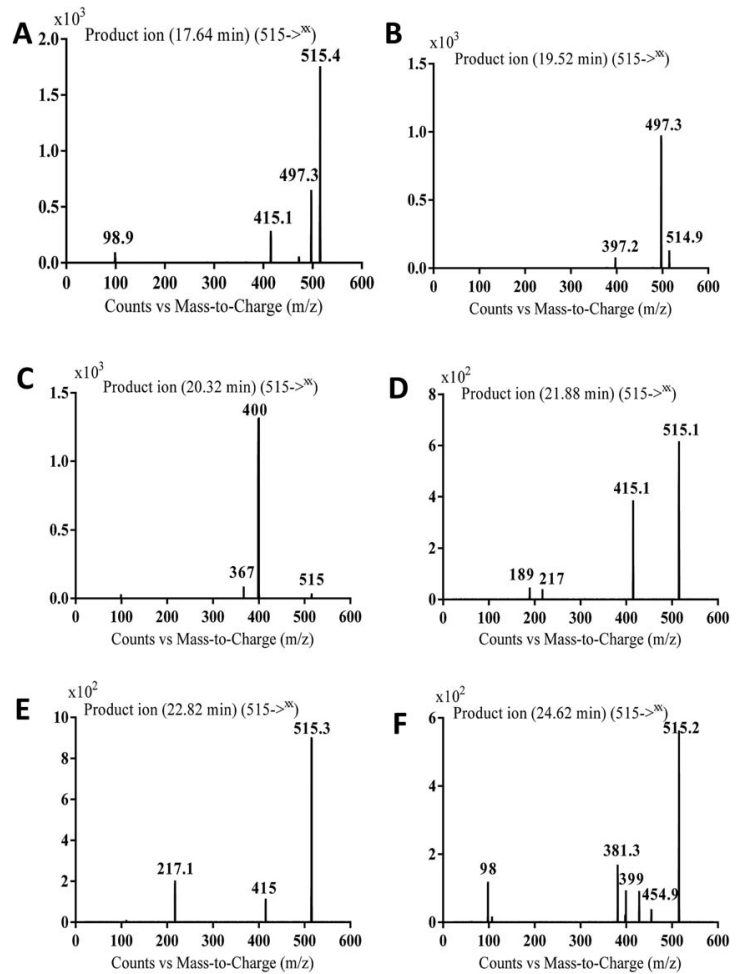

Fig. $7 M^{2}$ mass spectra of molecular ion peaks at $m / z$ 511: MA515a (A), MA515b (B), MA515c (C), MA515d (D), MA515e (E), and MA515f (F).

\subsection{RLMs incubations}

Thirty $\mu \mathrm{M}$ masitinib was incubated with $1.0 \mathrm{mg} \mathrm{mL}^{-1} \mathrm{RLMs}$ and $50 \mathrm{mM} \mathrm{Na} / \mathrm{K}$ phosphate buffer ( $\mathrm{pH} 7.4$ ) containing $3.3 \mathrm{mM}$ $\mathrm{MgCl}_{2}$ at $37{ }^{\circ} \mathrm{C}$ for $10 \mathrm{~min}$. Metabolic reaction was initiated by addition of $1.0 \mathrm{mM} \mathrm{NADPH}$ and quenched after $120 \mathrm{~min}$ by addition of $2 \mathrm{~mL}$ of ice-cold ACN. The incubation was done at
$37{ }^{\circ} \mathrm{C}$ in a shaking water bath for $120 \mathrm{~min}$. Proteins were removed by centrifugation ( $14000 \mathrm{rpm}, 10 \mathrm{~min}$ and $4{ }^{\circ} \mathrm{C}$ ). The supernatants were transferred to clean tubes and then evaporated to dryness under stream of $\mathrm{N}_{2}$. The residue was reconstituted in ACN/water $(1: 1)$. The same experiment was repeated using $1.0 \mathrm{mM}$ GSH or $1.0 \mathrm{mM} \mathrm{KCN}$ to capture bioactive metabolites. Similarly, negative control experiments were performed following the above procedures but without addition of masitinib, while positive control experiments were done without adding NADPH. All the control experiments data were provided as ESI file. $\dagger$

\subsection{Identification of in vitro phase I masitinib metabolites}

The detection of in vitro phase I masitinib metabolites was done by full MS scan and $\mathrm{MS}^{2}$ experiments. Extracted ion chromatogram (EIC) was used to locate metabolites in the total ion chromatogram (TIC) of the metabolic mixture. $\mathrm{MS}^{2}$ experiments were done for expected metabolites. $\mathrm{MS}^{2}$ mass spectra were used to elucidate the metabolite structure by reconstructing the marker fragment ions.

\section{Results and discussion}

\subsection{Fragmentation study of masitinib}

MS scan spectra of masitinib in LC-QqQ-MS show that masitinib molecular ion peak appears as $[\mathrm{M}+\mathrm{H}]^{+}$ion at $m / z 499$ and as $[\mathrm{M}+2 \mathrm{H}]^{2+}$ at $m / z 250$ (Fig. 2A). The $\mathrm{MS}^{2}$ mass spectrum for $[\mathrm{M}+$ $\mathrm{H}]^{+}$ion at $m / z 499$ gave only one major product ion at $m / z 399$ (Fig. 2B) which represent the loss of methyl piperazine group by single bond cleavage (Scheme 1).

Fragmentation of $[\mathrm{M}+2 \mathrm{H}]^{2+}$ at $m / z 250$ in LC-QqQ-MS gave more qualitative information about the weakest bonds in the masitinib chemical structure and gave many product ions compared to $[\mathrm{M}+\mathrm{H}]^{+}$as explained in Scheme 1 (Fig. 2C).

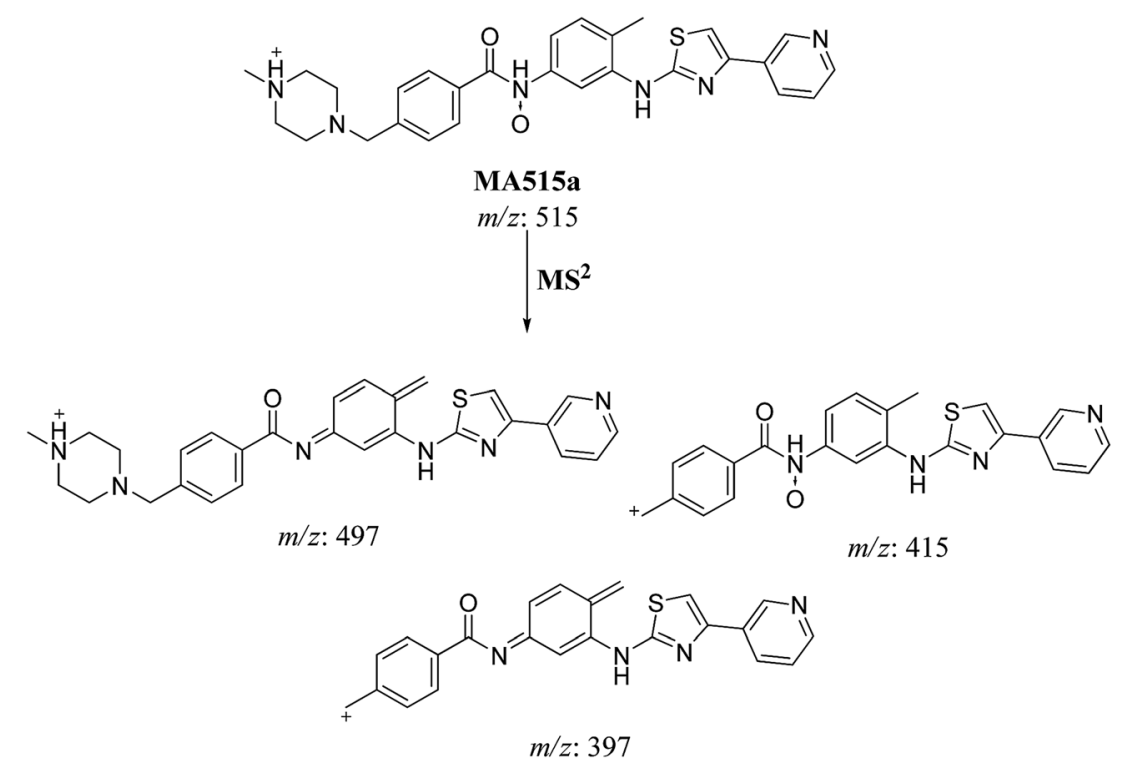

Scheme 5 Fragmentation pattern of MA515a. 


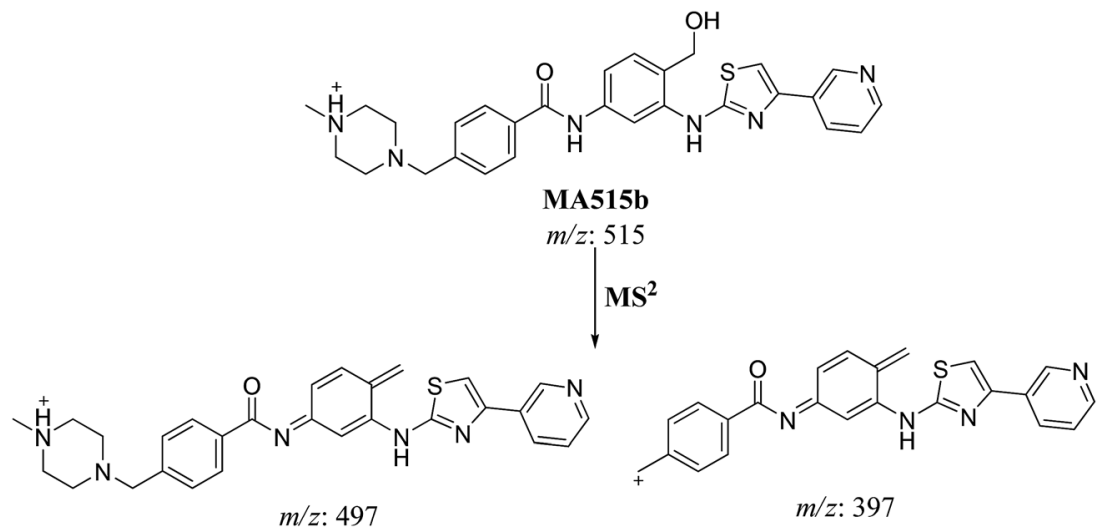

Scheme 6 Fragmentation pattern of MA515b.

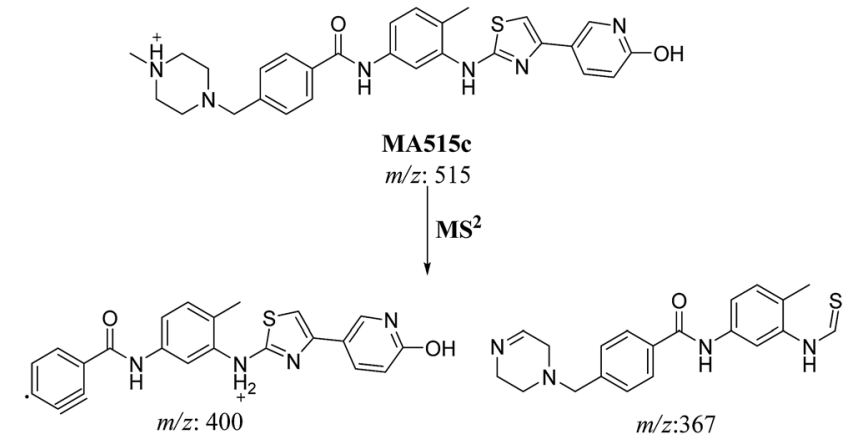

Scheme 7 Fragmentation pattern of MA515c.

\subsection{Identification of in vitro phase I masitinib metabolites}

Comparison of EIC between incubations mixture with control samples as well as comparison of $\mathrm{MS}^{2}$ mass spectra of masitinib and proposed metabolites (Table 1) allowed the detection of fourteen metabolites formed through five metabolic reactions (N-demethylation, N-oxidation, oxidation, reduction and hydroxylation). Fig. 3 shows the EICs of masitinib and its metabolites.

3.2.1. MA499a and MA499b phase I metabolites of masitinib. MA499a and MA499b metabolites of masitinib were detected at $m / z 499$ in full MS spectrum. MS $^{2}$ scan for molecular ion peak at $\mathrm{m} / \mathrm{z} 499$ gave fragment ions at $\mathrm{m} / \mathrm{z} 449,399$ and 217 for both metabolites but at two different retention times. The fragment ion at $\mathrm{m} / \mathrm{z} 399$ proposed that all metabolic changes happened in the $N$-methyl piperazine moiety. Metabolic reactions for MA499a and MA499b metabolites were proposed to be $\mathrm{N}$-demethylation and oxidation of piperazine carbon atom in masitinib at two different positions (Scheme 2) (Fig. 4).

3.2.2. MA485 phase I metabolite of masitinib. MA485 metabolite of masitinib was detected at $\mathrm{m} / \mathrm{z} 485$ in full MS spectrum. $\mathrm{MS}^{2}$ scan for molecular ion peak at $\mathrm{m} / \mathrm{z} 485$ gave fragment ion at $m / z 399$ (Fig. 5). The fragment ion at $m / z 399$ proposed that all metabolic changes happened in the $N$-methyl piperazine moiety. Metabolic reactions for MA485 metabolite was proposed to be N-demethylation (Scheme 3).

3.2.3. MA529 phase I metabolite of masitinib. MA529 metabolite of masitinib was detected at $\mathrm{m} / \mathrm{z} 529$ in full MS

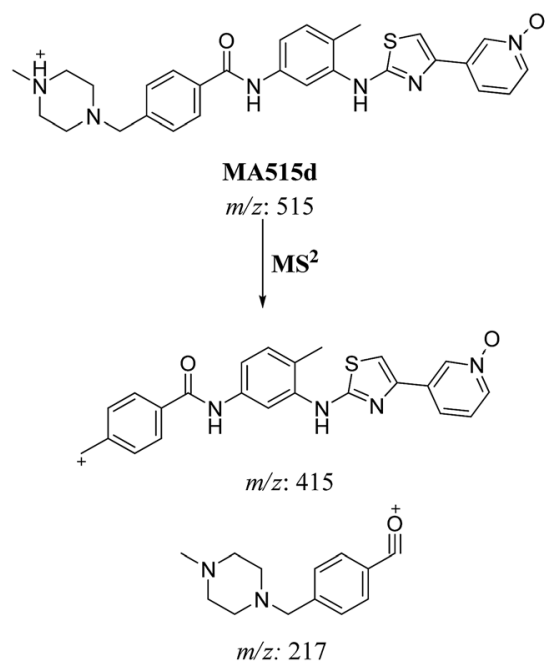<smiles>Cc1ccc(NC(=O)c2ccc(CN3CCN(C)CC3)cc2)cc1C(=O)Nc1nc(-c2cccnc2)cs1</smiles>

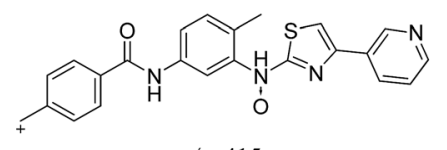

$m / z: 415$

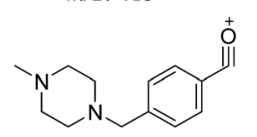

$m / z: 217$

Scheme 8 Fragmentation pattern of MA515d and MA515e. 

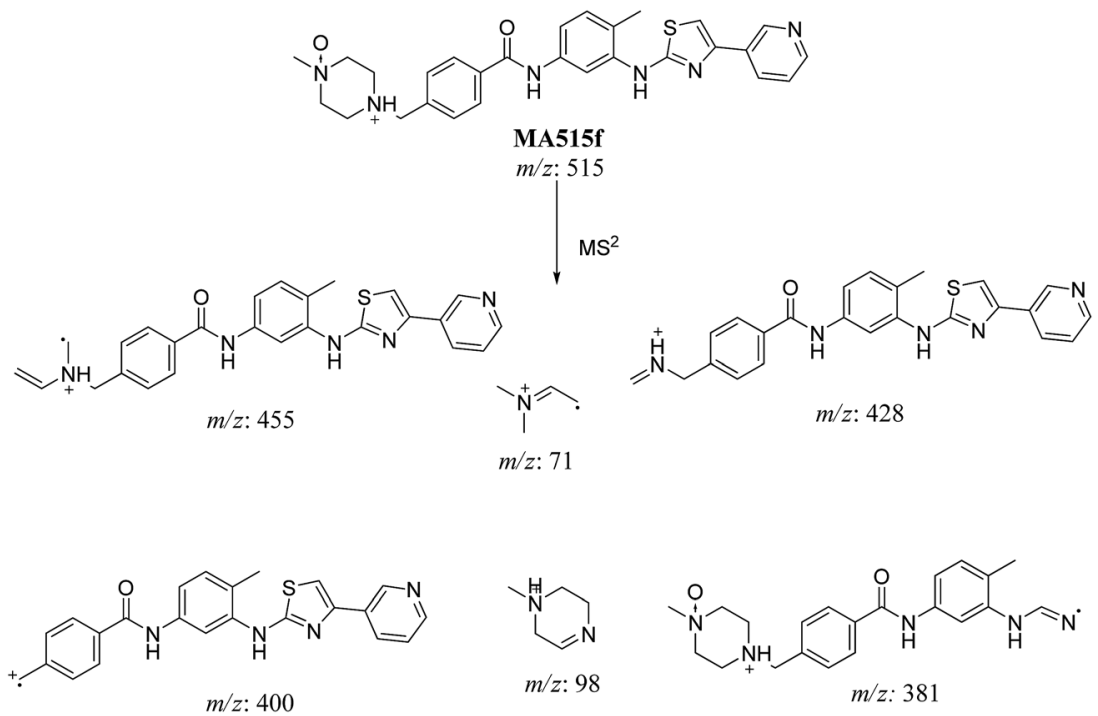

Scheme 9 Fragmentation pattern of MA515f.
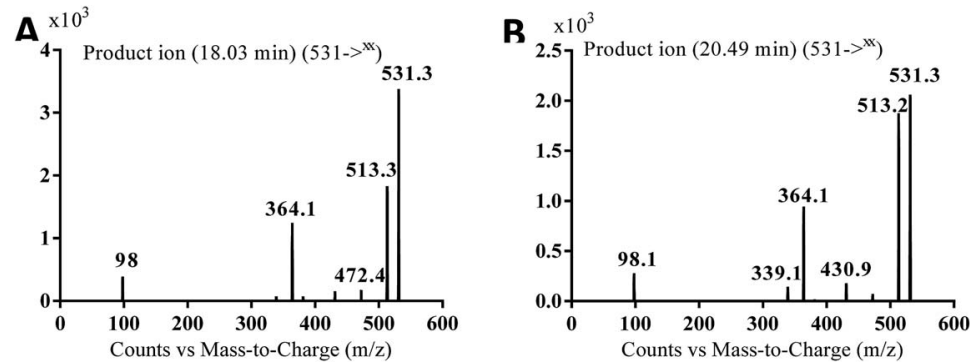

Fig. $8 M^{2}$ mass spectra of molecular ion peaks at $m / z$ 531: MA531a (A) and MA531b (B).<smiles>Cc1ccc(C(=O)Nc2ccc(CO)c(Nc3nc(-c4cccnc4)cs3)c2)cc1</smiles>

$m / z: 531$

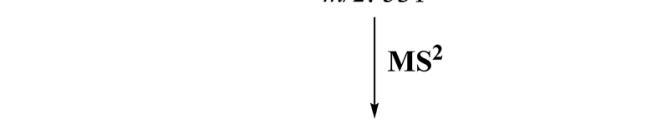<smiles>C=C1C=CC(=NC(=O)c2ccc(C)cc2)C=C1Nc1nc(-c2cccnc2)cs1</smiles><smiles>[134IH]</smiles><smiles>C=CN(C)Cc1ccc(C(=O)Nc2ccc(CO)c(Nc3nc(-c4cccnc4)cs3)c2)cc1</smiles>

$m / z: 472$

Scheme 10 Fragmentation pattern of MA531a. spectrum. $\mathrm{MS}^{2}$ scan for molecular ion peak at $m / z 529$ gave fragment ions at $m / z 511,399$ and 98 (Fig. 6). The fragment ion at $m / z 399$ proposed that all metabolic changes happened in the $\mathrm{N}$-methyl piperazine moiety. Metabolic reactions for MA485 metabolite was proposed to be hydroxylation and oxidation of piperazine carbon (Scheme 4).

3.2.4. MA515a to $f$ phase I metabolites of masitinib. MA515 a-f metabolites of masitinib were detected at $m / z 511$ in full MS spectrum. $\mathrm{MS}^{2}$ scan for molecular ion peaks at $\mathrm{m} / \mathrm{z} 515$ gave different fragment ions at different retention times (Fig. 7). Metabolic reactions for MA515a-f metabolites were proposed to be hydroxylation or N-oxide formation in masitinib.

The fragment ion at $\mathrm{m} / \mathrm{z} 415$ in $\mathrm{MS}^{2}$ mass spectrum of MA511a proposed that amide nitrogen underwent oxidation. So metabolic reactions for MA511a metabolite was proposed to be N-oxidation of amide nitrogen (Scheme 5). The fragment ions at $m / z 397$ and 497 in MS $^{2}$ mass spectrum of MA511b proposed the hydroxylation of benzylic carbon. So metabolic reactions for MA511b was proposed to be hydroxylation of benzylic carbon (Scheme 6).

In case of MA511c, the fragment ions at $m / z 400$ and 367 in $\mathrm{MS}^{2}$ mass spectrum proposed the hydroxylation of pyridine group. The fragment ion at $\mathrm{m} / \mathrm{z} 400$ proposed that hydroxylation 


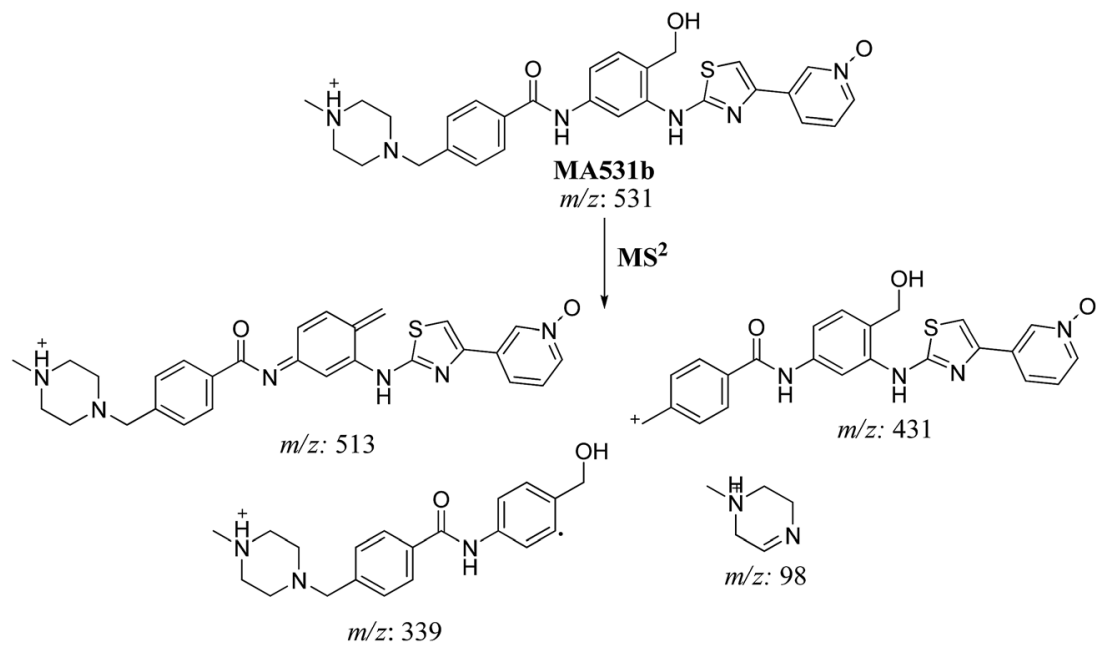

Scheme 11 Fragmentation pattern of MA531b.

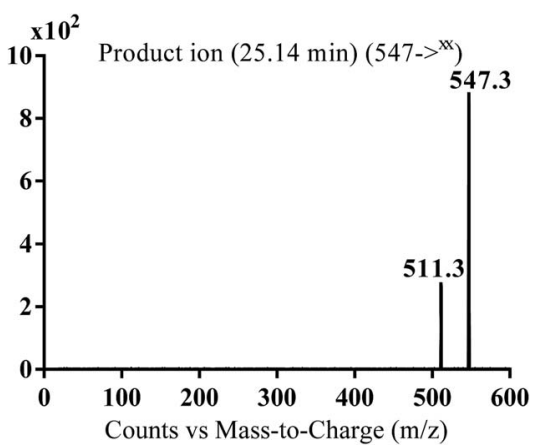

Fig. $9 \mathrm{MS}^{2}$ mass spectra of MA547 molecular ion peaks at $\mathrm{m} / \mathrm{z} 547$.

didn't happen in the $N$-methyl piperazine moiety. The fragment ion $m / z 367$ confirmed the proposal of hydroxylation of pyridine group (Scheme 7).

In case of MA511d and MA511e, the fragment ions at $\mathrm{m} / \mathrm{z} 415$ and 217 proposed the oxidation of pyridine nitrogen or oxidation of anilinic nitrogen (Scheme 8).

In case of MA511f, the fragment ions at $m / z 400,455$ and 428 proposed the N-oxidation at nitrogen atom of piperazine group. The fragment ion at $m / z 400$ in MA511f indicated that the loss of $n$-oxide methyl piperazine (Scheme 9).

3.2.5. MA531a and MA531b phase I metabolites of masitinib. MA531a and MA531b metabolites of masitinib were

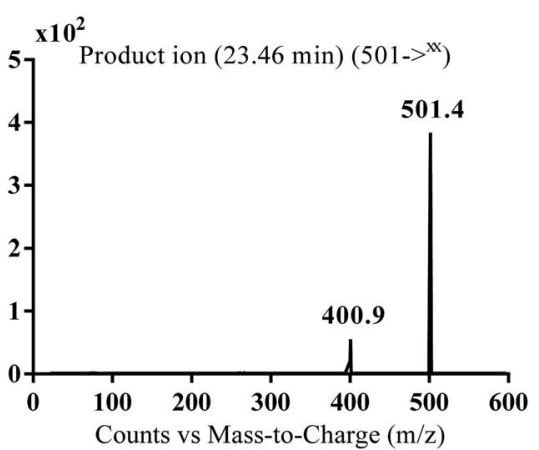

Fig. $10 M^{2}$ mass spectra of MA501 molecular ion peaks at $m / z 501$.

detected at $m / z 531$ in full MS spectrum. MS$^{2}$ scan for molecular ion peaks at $m / z 531$ gave different fragment ions (Fig. 8).

In case of MA531a and MS531b, the fragment ion at $\mathrm{m} / \mathrm{z} 513$ proposed the hydroxylation of benzylic carbon. The fragment ions at $\mathrm{m} / \mathrm{z} 431$ and $\mathrm{m} / \mathrm{z} 339$ proposed the oxidation of pyridine nitrogen. So MA531a is N-oxide of masitinib at piperazine nitrogen and hydroxylation of benzylic carbon and MA531b is $\mathrm{N}$-oxide of masitinib at pyridine nitrogen and hydroxylation of benzylic carbon (Scheme 10 and 11).

3.2.6. MA547 phase I metabolite of masitinib. MA547 metabolite of masitinib was detected at $m / z 547(\mathrm{M}+48)$ in full MS spectrum. $\mathrm{MS}^{2}$ scan for molecular ion peak at $m / z 547$ gave<smiles>CN1CCN(C)CC1</smiles>

MA547

$\mathrm{m} / z: 547$<smiles></smiles>

$m / z: 511$

Scheme 12 Fragmentation pattern of MA547. 
<smiles>Cc1cc(NC(O)c2ccc(-c3csc(Nc4cc(NC(O)c5ccc(F)cc5)ccc4C)n3)cn2)ncc1Nc1nc(-c2cccnc2)cs1</smiles>

Scheme 13 Fragmentation pattern of MA501.

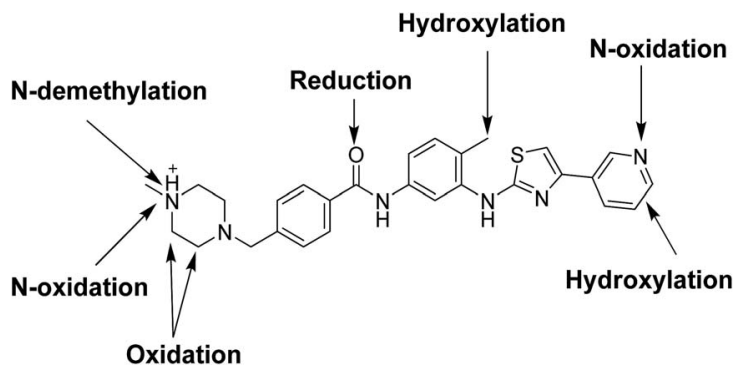

Fig. 11 Chemical structure of masitinib and proposed phase I metabolic reactions.

fragment ions at $m / z 511$ (Fig. 9). Metabolic reactions for MA547 metabolite was proposed to be hydroxylation of benzylic carbon, oxidation of pyridine nitrogen and oxidation of piperazine nitrogen (Scheme 12).

3.2.7. MA501 phase I metabolite of masitinib. MA501 metabolite of masitinib was detected at $\mathrm{m} / \mathrm{z} 501$ in full MS spectrum. $\mathrm{MS}^{2}$ scan for molecular ion peak at $\mathrm{m} / \mathrm{z} 501$ gave fragment ions at $m / z 401$ indicating that there is no change in the methyl piperazine group (Fig. 10). Metabolic reaction for MA501 metabolite was proposed to be reduction of carbonyl group (Scheme 13).

Fig. 11 shows the chemical structure of masitinib and identified metabolic processes in RLMs.

\subsection{Bioactive metabolites}

No GSH adducts were detected in the case of incubation with RLMs and $1.0 \mathrm{mM}$ GSH but in case of incubation with RLMs and 1.0 $\mathrm{mM} \mathrm{KCN}$, eight cyano adducts were detected as listed in Table 2 .

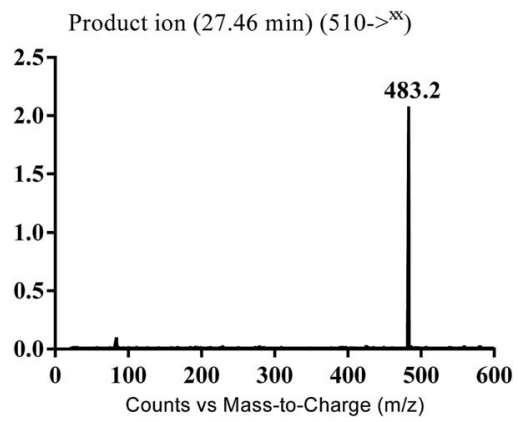

Fig. $12 M^{2}$ mass spectra of MB510 molecular ion peaks at $m / z 510$.<smiles>Cc1ccc(NC(=O)c2ccc(C[NH+]3CCNC(C#N)C3)cc2)cc1Nc1nc(-c2cccnc2)cs1</smiles>

MB510

$\mathrm{m} / \mathrm{z}: 510$ $\mathrm{MS}^{2}$<smiles>Cc1ccc(NC(=O)c2ccc(C[NH+]3C=CNCC3)cc2)cc1Nc1nc(-c2cccnc2)cs1</smiles>

Scheme 14 Fragmentation pattern of MB510.

Table 2 Masitinib cyano adducts

\begin{tabular}{lllll}
\hline & MS scan & MS $^{2}$ product ions & $t_{\mathrm{R}}(\mathrm{min})$ & Metabolic reaction \\
\hline MB510 & 510 & 483 & 27.5 & Cyano conjugation and N-demethylation \\
MB526 & 526 & $499,481,401,92$ & 28.9 & Cyano conjugation and carbonyl reduction \\
MB538a & 538 & 511 & 30.3 & Cyano conjugation and oxidation \\
MB538b & 538 & 511 & 31.0 & Cyano conjugation and oxidation \\
MB538c & 538 & 511,399 & 32.5 & Cyano conjugation and oxidation \\
MB524a & 524 & 497 & 24.2 & $\begin{array}{l}\text { Cyano conjugation, oxidation and } \\
\text { N-demethylation }\end{array}$ \\
MB524b & 524 & 497 & 28.1 & $\begin{array}{l}\text { Cyano conjugation, oxidation and } \\
\text { N-demethylation }\end{array}$ \\
MB524c & 524 & 497,399 & 30.4 & Cyano conjugation, oxidation and \\
& & & &
\end{tabular}




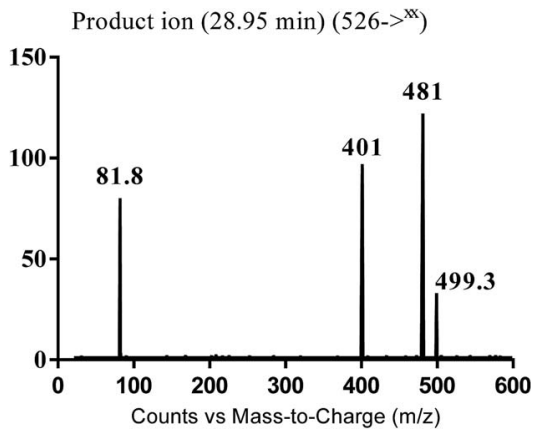

Fig. $13 \mathrm{MS}^{2}$ mass spectra of MB526 molecular ion peaks at $m / z 526$.

3.3.1. Identification of MB510 metabolite of masitinib. MB510 cyano adduct of masitinib was detected at $\mathrm{m} / z 510$ in full MS spectrum. $\mathrm{MS}^{2}$ scan for molecular ion peak at $\mathrm{m} / z 510$ gave fragment ion at $m / z 483$ (Fig. 12). The fragment ion at $\mathrm{m} / \mathrm{z} 483$ proposed the immediate loss of a molecule of hydrogen cyanide (Scheme 14). Metabolic reactions for MB526 cyano adduct were proposed to be $\mathrm{N}$-demethylation and addition of cyano group to the piperazine ring.

3.3.2. Identification of MB526 metabolite of masitinib. MB526 cyano adduct of masitinib was detected at $\mathrm{m} / z 526$ in full MS spectrum. $\mathrm{MS}^{2}$ scan for molecular ion peak at $\mathrm{m} / z 526$ gave fragment ions at $m / z 499,481$ and 401 (Fig. 13). The fragment ion at $\mathrm{m} / \mathrm{z} 499$ proposed the immediate loss of a molecule of hydrogen cyanide while the fragment ion at $\mathrm{m} / \mathrm{z} 401$ proposed that the addition of the cyano group occurred in the piperazine ring, which was consistent with the fragment ion at $\mathrm{m} / \mathrm{z} 481$ (Scheme 15). Metabolic reactions for MB526 cyano adduct were proposed to be reduction of carbonyl group and addition of cyano group to the piperazine ring.

3.3.3. Identification of MB538a to $\mathrm{c}$ metabolite of masitinib. MB538a, MB538b and MB538c cyano adducts of masitinib were detected at $m / z 538$ in full MS spectrum. MS $^{2}$ scan for
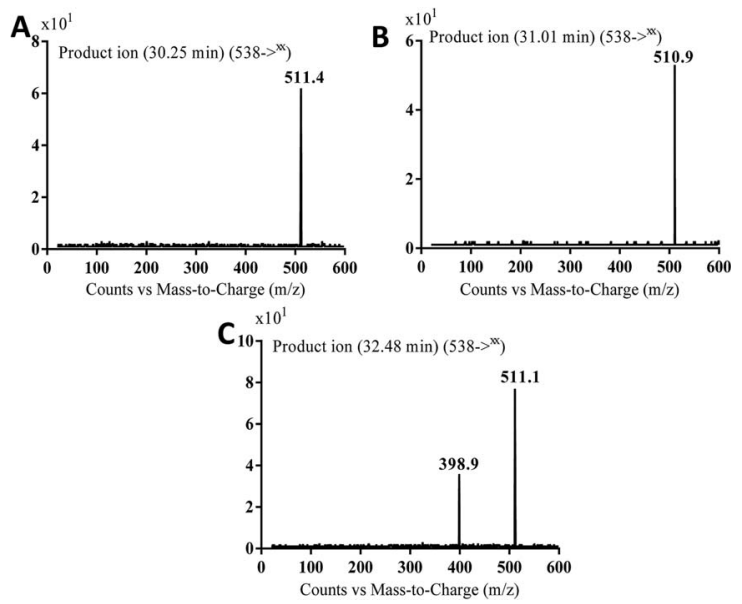

Fig. $14 M^{2}$ mass spectra of molecular ion peaks at $m / z$ 538: MB538a (A), MB538b (B) and MB538c (C).

molecular ion peaks at $m / z 538$ gave similar fragment ions but at different retention times. Fragmentation of molecular ion at $\mathrm{m} / \mathrm{z} 538$ (Fig. 14), the molecule underwent an immediate loss of a molecule of hydrogen cyanide and formed product ion $\mathrm{m} / \mathrm{z}$ 511. Metabolic reactions for MB538a, MB538b and MB538c adducts were proposed to be oxidation of $\alpha$-carbon and addition of cyano group in the activated $\alpha$-carbon of piperazine group at different positions (Scheme 16).

3.3.4. Identification of MB524a to c metabolite of masitinib. MB524a, MB524b, and MB524c cyano adducts of masitinib were detected at $m / z 524$ in full MS spectrum. MS $^{2}$ scan for molecular ion peaks at $m / z 524$ gave similar fragment ions but at different retention times. Fragmentation of molecular ion at $\mathrm{m} /$ $z 524$ (Fig. 15), the molecule underwent an immediate loss of a molecule of hydrogen cyanide and formed product ion $\mathrm{m} / \mathrm{z}$ 497. Metabolic reactions for MB524a, MB524b and MB524c

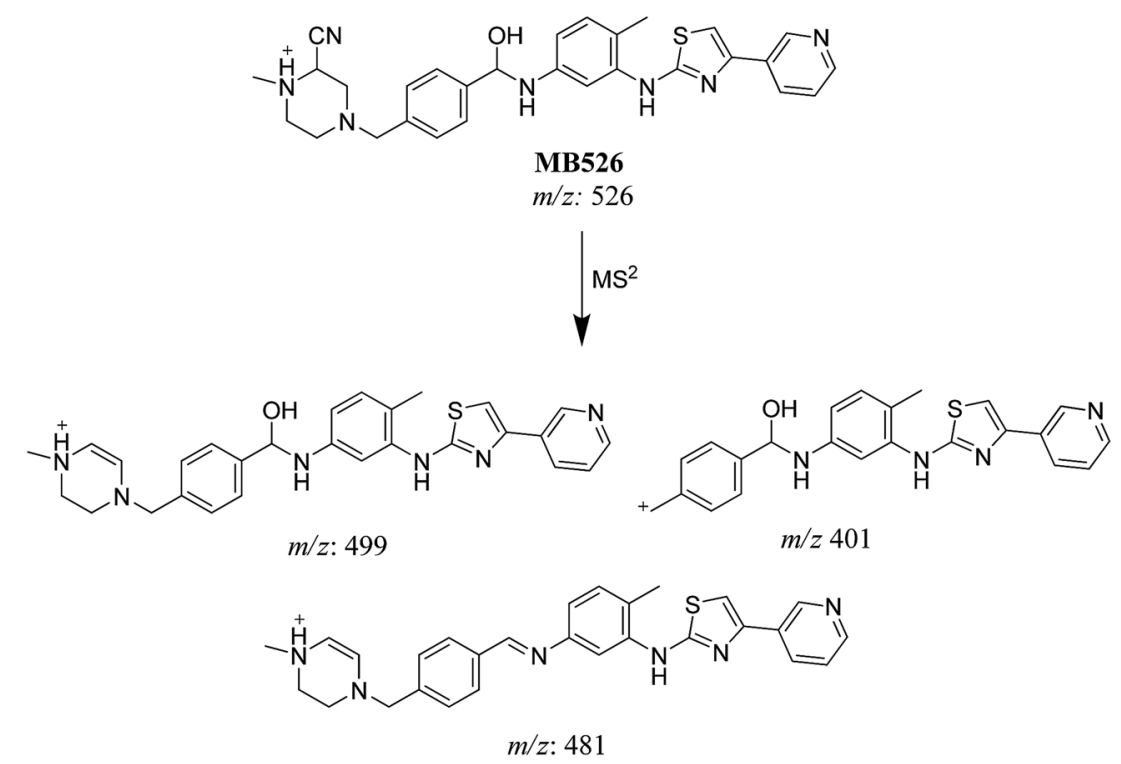

Scheme 15 Fragmentation pattern of MB526 


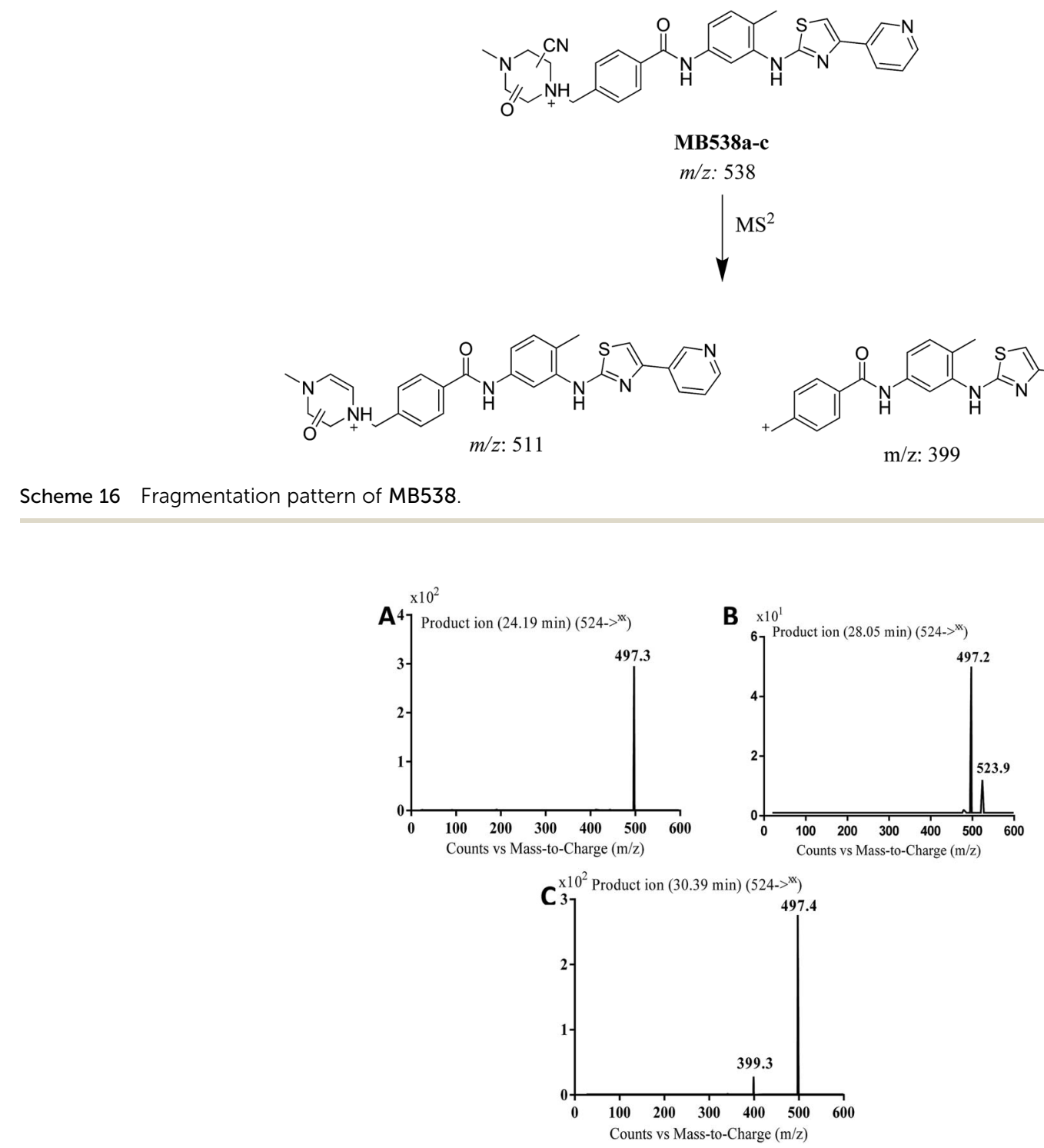

Fig. 15 MS $^{2}$ mass spectra of molecular ion peaks at $m / z$ 524: MB524a (A), MB524b (B) and MB524c (C).<smiles>Cc1ccc(NC(=O)c2ccc(Nc3nc(-c4cccnc4)cs3)cc2)cc1</smiles><smiles>Cc1ccc(NC(=O)c2ccc(CN3[C@@H]4C=C[C@H]3O4)cc2)cc1Nc1nc(-c2cccnc2)cs1</smiles><smiles>Cc1ccc(NC(=O)c2ccc(F)cc2)c(Nc2nc(-c3cccnc3)cs2)c1</smiles>

Scheme 17 Fragmentation pattern of MB524a to c. 


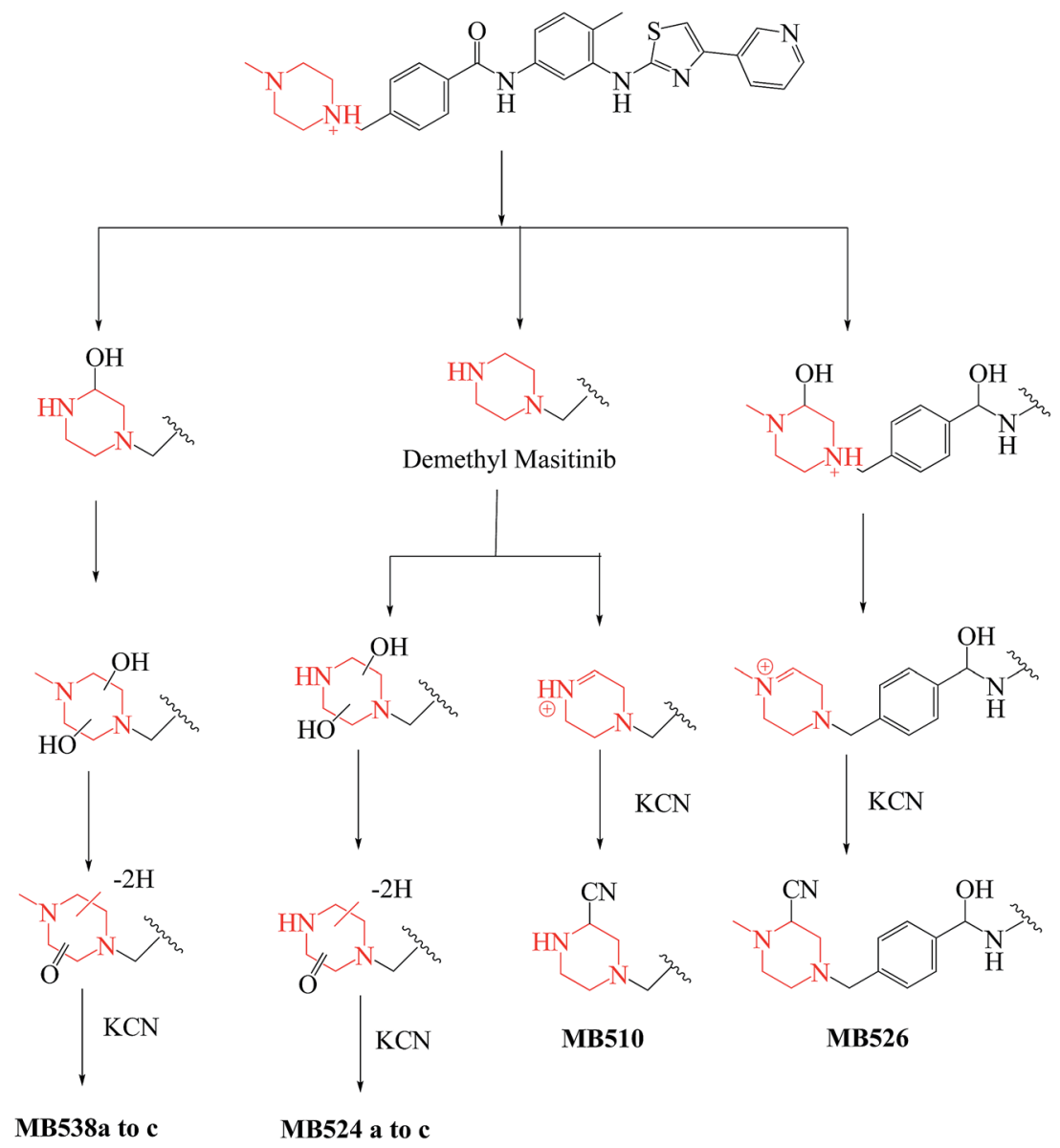

Scheme 18 Proposed bioactivation mechanisms of masitinib.

adducts were proposed to be demethylation of methylpiperazine group then oxidation of piperazine $\alpha$-carbon and addition of cyano group in the activated $\alpha$-carbon of piperazine group at different (Scheme 17).

\subsection{Bioactivation mechanism of masitinib}

Bioactivation pathways of masitinib were proposed as shown in Scheme 18. P450-catalyzed oxidation of piperazine ring in masitinib then dehydration resulted in formation of imine and imine-carbonyl intermediates. These reactive intermediates are not stable but can be trapped by cyanide forming stable adduct

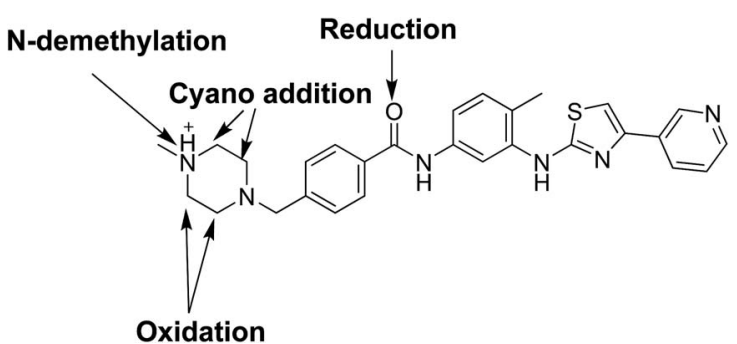

Fig. 16 Chemical structure of masitinib and identified cyano conjugates. that can be detected in the mass spectrometer. ${ }^{17}$ Place of cyano addition is proposed as shown in Fig. 16. The eight cyanide adducts are proposed as shown in Scheme 18 explaining the proposed mechanism of bioactivation of masitinib.

\section{Conclusions}

Fourteen metabolites were formed by incubation of masitinib with RLMs through five metabolic reactions: N-demethylation, $\mathrm{N}$ oxidation, oxidation, reduction and hydroxylation. No GSH adduct was detected when incubated with RLMs with $1.0 \mathrm{mM}$ GSH. Eight cyano adducts were detected when incubated with RLMs with $1.0 \mathrm{mM}$. All metabolic bioactivation reactions happened in the $N$-methyl piperazine moiety which may be the reason for instability and toxicity of masitinib.

\section{Conflict of interest}

The authors declare no conflict of interest.

\section{Acknowledgements}

The authors would like to extend their sincere appreciation to the Deanship of Scientific Research at the King Saud University for 
funding this work through the Research Group Project No. RGP322.

\section{References}

1 A. Jemal, R. Siegel, E. Ward, Y. Hao, J. Xu, T. Murray and M. J. Thun, Ca-Cancer J. Clin., 2008, 58, 71-96.

2 R. Sinha and K. El-Bayoumy, Curr. Cancer Drug Targets, 2004, 4, 13-28.

3 P. Cozzi, N. Mongelli and A. Suarato, Curr. Med. Chem.: AntiCancer Agents, 2004, 4, 93-121.

4 M. Barinaga, Science, 1997, 278, 1036-1039.

5 J. Schlessinger, Cell, 2000, 103, 211-225.

6 C. Özvegy-Laczka, J. Cserepes, N. B. Elkind and B. Sarkadi, Drug Resist. Updates, 2005, 8, 15-26.

7 N. Steeghs, J. W. Nortier and H. Gelderblom, Ann. Surg. Oncol., 2007, 14, 942-953.

8 C. Natoli, B. Perrucci, F. Perrotti, L. Falchi and S. Iacobelli, Curr. Cancer Drug Targets, 2010, 10, 462-483.

9 K. Hahn, G. Oglivie, T. Rusk, P. Devauchelle, A. Leblanc, A. Legendre, B. Powers, P. Leventhal, J. P. Kinet and F. Palmerini, J. Vet. Intern. Med., 2008, 22, 1301-1309.
10 M. Daly, S. Sheppard, N. Cohen, M. Nabity, A. Moussy, O. Hermine and H. Wilson, J. Vet. Intern. Med., 2011, 25, 297-302.

11 I. Marech, R. Patruno, N. Zizzo, C. Gadaleta, M. Introna, A. F. Zito, C. D. Gadaleta and G. Ranieri, Critical Reviews in Oncology/Hematology, 2014, 91, 98-111.

12 P. Dubreuil, S. Letard, M. Ciufolini, L. Gros, M. Humbert, N. Castéran, L. Borge, B. Hajem, A. Lermet and W. Sippl, PLoS One, 2009, 4, e7258.

13 T. A. Baillie, Chem. Res. Toxicol., 2006, 19, 889-893.

14 A. S. Kalgutkar, I. Gardner, R. S. Obach, C. L. Shaffer, E. Callegari, K. R. Henne, A. E. Mutlib, D. K. Dalvie, J. S. Lee and Y. Nakai, Curr. Drug Metab., 2005, 6, 161-225.

15 A. F. Stepan, D. P. Walker, J. Bauman, D. A. Price, T. A. Baillie, A. S. Kalgutkar and M. D. Aleo, Chem. Res. Toxicol., 2011, 24, 1345-1410.

16 R. von Jagow, H. Kampffmeyer and M. Kinese, Naunyn Schmiedebergs Arch. Exp. Pathol. Pharmakol., 1965, 251, 7387.

17 D. Argoti, L. Liang, A. Conteh, L. Chen, D. Bershas, C.-P. Yu, P. Vouros and E. Yang, Chem. Res. Toxicol., 2005, 18, 15371544 . 